\title{
A Transient Receptor Potential-Like Channel Mediates Synaptic Transmission in Rod Bipolar Cells
}

\author{
Yin Shen, ${ }^{1,2}$ J. Alexander Heimel, ${ }^{3}$ Maarten Kamermans, ${ }^{4,5}$ Neal S. Peachey, ${ }^{6,78}$ Ronald G. Gregg, ${ }^{9,10}$ and Scott Nawy ${ }^{1,2}$ \\ ${ }^{1}$ Departments of Ophthalmology and Visual Sciences and ${ }^{2}$ Dominick P. Purpura Department of Neuroscience, Albert Einstein College of Medicine, Bronx, \\ New York 10461, ${ }^{3}$ Molecular Visual Plasticity Group and ${ }^{4}$ Research Unit Retinal Signal Processing, The Netherlands Institute for Neuroscience, Royal \\ Netherlands Academy of Arts and Sciences, 1105 BA Amsterdam, The Netherlands, ${ }^{5}$ Department of Neurogenetics, Academic Medical Center, University of \\ Amsterdam, 1105 AZ Amsterdam, The Netherlands, ${ }^{6}$ Cleveland Veterans Affairs Medical Center, Cleveland, Ohio 44196, ${ }^{7}$ Cole Eye Institute, \\ Cleveland Clinic Foundation, Cleveland, Ohio 44195, ${ }^{8}$ Department of Ophthalmology, Cleveland Clinic Lerner College of Medicine of Case Western Reserve \\ University, Cleveland, Ohio 44106, and Departments of ${ }^{9}$ Biochemistry and Molecular Biology and ${ }^{10}$ Ophthalmology and Visual Sciences, University of \\ Louisville, Louisville, Kentucky 40202
}

On bipolar cells are connected to photoreceptors via a sign-inverting synapse. At this synapse, glutamate binds to a metabotropic receptor which couples to the closure of a cation-selective transduction channel. The molecular identity of both the receptor and the $\mathrm{G}$ protein are known, but the identity of the transduction channel has remained elusive. Here, we show that the transduction channel in mouse rod bipolar cells, a subtype of On bipolar cell, is likely to be a member of the TRP family of channels. To evoke a transduction current, the metabotropic receptor antagonist LY341495 was applied to the dendrites of cells that were bathed in a solution containing the mGluR6 agonists L-AP4 or glutamate. The transduction current was suppressed by ruthenium red and the TRPV1 antagonists capsazepine and SB-366791. Furthermore, focal application of the TRPV1 agonists capsaicin and anandamide evoked a transduction-like current. The capsaicin-evoked and endogenous transduction current displayed prominent outward rectification, a property of the TRPV1 channel. To test the possibility that the transduction channel is TRPV1, we measured rod bipolar cell function in the TRPV1 ${ }^{-I-}$ mouse. The ERG b-wave, a measure of On bipolar cell function, as well as the transduction current and the response to TRPV1 agonists were normal, arguing against a role for TRPV1. However, ERG measurements from mice lacking TRPM1 receptors, another TRP channel implicated in retinal function, revealed the absence of a b-wave. Our results suggest that a TRP-like channel, possibly TRPM1, is essential for synaptic function in On bipolar cells.

\section{Introduction}

Glutamate hyperpolarizes On bipolar cells by closing a cationselective channel (Shiells et al., 1981; Slaughter and Miller, 1981). The glutamate receptor (Nakajima et al., 1993; Nomura et al., 1994) and the G protein (Vardi et al., 1993; Nawy, 1999; Dhingra et al., 2000) that mediate this response have been identified, but the cation channel has not. Two major families of cation-selective channels are the cyclic nucleotide-gated channels (CNG) (Craven and Zagotta, 2006) and the transient receptor potential (TRP) channels (Ramsey et al., 2006). Previous studies of On bipolar transduction suggested that the cation channel may be a member of the CNG family of channels, based on the observation that cGMP strongly potentiates the current (Nawy and Jahr, 1990; Shiells and Falk, 1990). However, it was later shown that the

Received Jan. 10, 2009; revised March 12, 2009; accepted March 15, 2009.

This work was supported by National Eye Institute Grants EY010254 (S.N.) and EY12354 (R.G.G.), Foundation Fighting Blindness, Research to Prevent Blindness, Veterans Affairs Medical Research Service (N.S.P.), SenterNovem Grant BSIK 03053 (J.A.H.), and the Wellccome Trust for providing funds for distribution of the TRPM1 ${ }^{-1-}$ mice. TRPM1 ${ }^{-1-}$ ERGs were done in the laboratory of Dr. Christiaan N. Levelt by J.A.H. with initial help of Jochem Cornelis and discussions with Dr. Reed Carroll.

Correspondence should be addressed to Yin Shen, Dominick P. Purpura Department of Neuroscience, Albert Einstein College of Medicine, Bronx, NY 10461. E-mail: yshen@aecom.yu.edu.

D0I:10.1523/JNEUROSCI.0132-09.2009

Copyright $\odot 2009$ Society for Neuroscience $\quad$ 0270-6474/09/296088-06\$15.00/0 channel is unlikely to be gated directly by cGMP, but rather that cGMP has a modulatory role (Nawy, 1999; Snellman and Nawy, 2004).

In the vertebrate retina, pharmacological evidence suggests that a member of the TRP channel family is likely expressed in light-sensitive ganglion cells (Warren et al., 2006; Hartwick et al., 2007; Sekaran et al., 2007). In On bipolar cells, two types of TRP channels have emerged as candidates for the transduction channel. One candidate is TRPV1, which is expressed predominantly in the peripheral nervous system and mediates heat sensation. Both TRPV1 and the On bipolar cell transduction channel are moderately permeable to $\mathrm{Ca}^{2+}$ with a $\mathrm{Ca}^{2+} / \mathrm{Na}^{+}$permeability ratio of 9.6 in TRPV1 channels expressed in oocytes (Caterina et al., 1997) and 4.9 in salamander On bipolar cells (Nawy, 2000). The entry of $\mathrm{Ca}^{2+}$ activates a negative feedback pathway leading to desensitization of both the On bipolar cell transduction current (Shiells and Falk, 1999; Nawy, 2000; Berntson et al., 2004; Nawy, 2004) and the response to heat and capsaicin mediated by TPRV1 (Liu and Simon, 1996; Caterina et al., 1997; Koplas et al., 1997; Piper et al., 1999). Here, we present evidence that the transduction channel can be activated by both capsaicin and anandamide, compounds that are thought to be specific agonists for TRPV1. Another candidate channel is the founding member of the family of melastatin-related TRP channels (TRPM1). Recent 
A
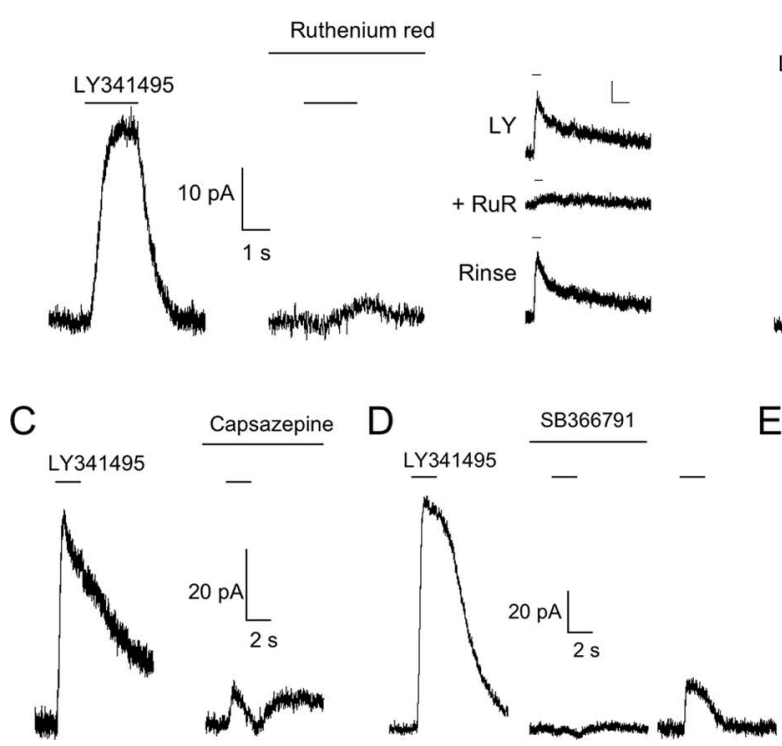

$E$

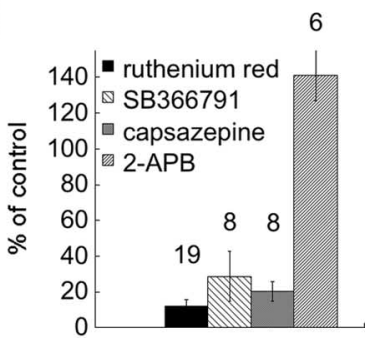

Figure 1. The rod bipolar cell transduction current is blocked by antagonists of TRPV1. A, Response to $100 \mu \mathrm{M}$ LY341495 (delivered via fast-flow apparatus) before (left) and after (center) a 5 min application of $10 \mu \mathrm{m}$ ruthenium red. Right, Response of another cell to a $1 \mathrm{~s}$ puff of LY341495 delivered through a puffer pipette alone (top) or during simultaneous application of ruthenium red from a second puffer pipette (middle). Ruthenium red was applied alone for $10 \mathrm{~s}$ before obtaining the middle trace. The inhibition of ruthenium red was readily reversed using this approach (bottom). Calibration: 10 pA, 2 s. B, Response to LY341495 before and after a 5 min application of $100 \mu \mathrm{m} 2$-APB. C, $D$, Responses to $1 \mathrm{~s}$ puffs of LY341495 $(100 \mu \mathrm{m})$ before and after 5 min bath application of $20 \mu \mathrm{m}$ capsazepine (C) and $20 \mu \mathrm{m}$ SB366791 (D). Responses to LY341495 typically showed partial recovery after removal of antagonists, as shown in the right panel of $\boldsymbol{D}$. Traces in $\boldsymbol{C}$ and $\boldsymbol{D}$ are from different cells. $\boldsymbol{E}$, Summary of results. The number of cells for each experiment is indicated above each bar.

studies of Appaloosa horses have demonstrated that a dramatic reduction in the expression of mRNA encoding TRPM1 is a possible cause of night blindness and a reduced b-wave in the ERGs (Sandmeyer et al., 2007; Bellone et al., 2008). Both are indicative of a disruption of On bipolar cell function, implying that TRPM1 may play a role in mGluR6 signal transduction. We, therefore, set out to characterize the functional properties of the transduction channel and to further evaluate the possibility that it is composed of TRPV1 or TRPM1 subunits.

\section{Materials and Methods}

Preparation of slices. Retinal slices from 4- to 6-week-old C57BL/6 mice (Charles River) and TRPV1 knock-out mice (Trpv1 $1^{\text {tmIJul}}$; The Jackson Laboratory) were prepared as described previously (Snellman and Nawy, 2004). Briefly, after killing, whole retinas were isolated and placed on a $0.65 \mu \mathrm{m}$ cellulose acetate/nitrate membrane filter (Millipore), secured with vacuum grease to a glass slide adjacent to the recording chamber. Slices were cut to a thickness of $100 \mu \mathrm{m}$ using a tissue slicer (Stoelting), transferred to the recording chamber while remaining submerged, and viewed with a Nikon E600FN upright microscope equipped with a waterimmersion $40 \times$ objective and differential interference contrast optics.

Solutions and drug application. Slices were continuously perfused with Ames media bubbled with $95 \% \mathrm{O}_{2} / 5 \% \mathrm{CO}_{2}$. Picrotoxin $(100 \mu \mathrm{M})$, strychnine $(10 \mu \mathrm{M})$, and TPMPA (1,2,5,6-tetrahydropyridin-4-yl methylphosphinic acid; $50 \mu \mathrm{M}$ ) were included in all experiments to block inhibitory conductances. Patch pipettes of resistance 7-9 $M \Omega$ were fabricated from borosilicate glass (WPI) using a two-stage vertical puller (Narishige), and filled with a $\mathrm{K}^{+}$gluconate-based solution that also contained 0.5 mм EGTA, 10 mм HEPES, 4 mм ATP, and 1 mm GTP (pH 7.4 by $\mathrm{CsOH}$ ) and $14 \mu \mathrm{g} / \mathrm{ml}$ Alexa 488 (Invitrogen). In some experiments, the metabotropic receptor antagonist LY341495, or TRP channel reagents, were delivered to the retina from a pipette using positive pressure (2-4 PSI) with a computer-controlled solenoid valve (Picospritzer; Gen- eral Valve), and the mGluR6 agonist L-AP4 (4 $\mu \mathrm{M})$ was added to the bath. In other experiments, drugs were applied via a fast-flow apparatus (Snellman and Nawy, 2004), and glutamate was used as an mGluR6 agonist. Drugs and chemicals were purchased from Sigma, with the exceptions of L-AP4 and LY341495 (Tocris Bioscience) and AM251 (Caymen Chemical).

Recording and analysis. Whole-cell recordings were obtained with an Axopatch 1D amplifier (Molecular Devices). Currents were acquired at a sampling rate of $2 \mathrm{kHz}$ with Axograph X software and an Apple G5 computer, low-pass filtered at $50 \mathrm{~Hz}$ (Frequency Devices) and digitized with an ITC-18 interface (Heka). Holding potentials were corrected for the liquid junction potential, which was measured to be $10 \mathrm{mV}$ with the standard $\mathrm{K}^{+}$gluconate pipette solution. Recordings were discarded if the series resistance exceeded $20 \mathrm{M} \Omega$. Data were analyzed off-line with Axograph X and Kaleidagraph (Synergy Software). Plots of normalized conductance of the transduction channel versus voltage were fit with a Boltzmann relation of the form $g=\left(g_{\max }-g_{\min }\right) /(1$ $\left.+\exp \left(\left(V_{\mathrm{m}}-V_{1 / 2}\right) /-k\right)\right)+g_{\min }$, where $g_{\max }$ is the maximum conductance, $g_{\min }$ is the minimum conductance, $V_{1 / 2}$ is the voltage at which the conductance is half of maximum, and $k$ is the slope factor $R T / z F$, where $z$ is the valance of the gating charge. Holding potential for all cells was $+40 \mathrm{mV}$, unless indicated otherwise.

ERGs were recorded to flash stimuli presented to the dark-adapted eye from TRPV1 ${ }^{-1-}$ mice using a previously described procedure (Gregg et al., 2007) and from TRPM1 $1^{-/-}$mice using a procedure that was generally similar but used a different anesthetic (urethane, $2 \mathrm{~g} / \mathrm{kg}$ ), maximum stimulus duration ( $5 \mathrm{~ms})$, and sampling rate $(10 \mathrm{kHz})$. The a-wave was measured at $8 \mathrm{~ms}$ from the prestimulus baseline, whereas the b-wave was measured from the a-wave trough to the positive peak.

TRPM $1^{-1-}$ mice were generated by Lexicon Genetics (Trpm $1^{\mathrm{tm} 1 \text { Lex }}$ ) and obtained from the European Mouse Mutant Archive. Molecular details of the targeted allele are available at http://www.emmanet.org/. The targeted allele deletes $212 \mathrm{bp}$ from exon 3 and all of exons 4 and 5 (accession \#AY180104). This will produce a frameshift mutation in the transcript terminating translation at amino acid 79. Although there are several splice variants listed on Ensemble (www.ensemble.org), this deletion would truncate all the splice variants. The genotype of the mice was confirmed by PCR using $1 \mu \mathrm{M}$ of each primer (LexKo-428-31, GCATAGTCCATGGACCTAGC; Neo3a, GCAGCGCATCGCCTTCTATC; trp-82, TGCAGCTTTGATTCACATCAT) and Accuprime Taq polymerase in Buffer II as described by the manufacturer (Invitrogen), yielding fragments of $319 \mathrm{bp}$ for the wild-type (WT) and $280 \mathrm{bp}$ for the mutant allele.

\section{Results \\ The rod bipolar cell transduction current is inhibited by TRP antagonists}

To test the hypothesis that the transduction channel is a member of the TRP family, we first examined the effects of compounds known to antagonize TRP channels on the rod bipolar cell transduction current. To evoke a transduction current, rod bipolar cells were bathed in either $1 \mathrm{~mm}$ glutamate or $4 \mu \mathrm{M} \mathrm{L}-\mathrm{AP} 4$ and then exposed to brief applications of the mGluR antagonist LY341495 $(100 \mu \mathrm{M})$. Blockade of mGluR6 resulted in the opening of the transduction channel which, at positive voltages, generated an outward current (Fig. 1A) (mean amplitude, $30.4 \pm 3.0 \mathrm{pA}$; 
$n=58)$. Using this approach, we were able to measure the transduction current for extended periods of time without any significant rundown, as reported previously (Snellman and Nawy, 2004). Application of $10 \mu \mathrm{M}$ ruthenium red, a noncompetitive antagonist of most TRPV and TRPC channels (Clapham, 2007) using either a fast-flow apparatus (see Materials and Methods) (Fig. $1 A$, left, center panels) or a puffer pipette (Fig. $1 A$, right panel), reduced the transduction current to an average of $15.3 \pm 2.5 \%$ of control (Fig. 1E). When applied via puffer pipette, the effects of ruthenium red were readily reversible. Conversely, application of 2-aminoethoxydiphenyl borate (2-APB), which is an antagonist at many TRPC channels, but an agonist at TRPV channels (Clapham, 2007), potentiated the transduction current (Fig. $1 B$ ) to $141 \pm 14.1 \%$ of control (Fig. 1E).

This pharmacological profile is consistent with a TRPV-like channel. In an attempt to further narrow this profile, we examined the effects of capsazepine and SB366791, which have been reported to be specific antagonists for TRPV1 (Caterina et al., 1997). Both compounds dramatically reduced the size of the transduction current (Fig. 1C,D), SB366791, to $28.7 \pm 14.1 \%$ of control and capsazepine to $20.4 \pm 5.6 \%$ of control (Fig. $1 E)$.

\section{TRPV1 agonists evoked a current with properties that are similar to the transduction current}

Our results suggest that TRPV1 antagonists are capable of blocking the gating of the transduction channel by the endogenous activator of the channel. We, therefore, tested the possibility that TRPV1 agonists can activate the rod bipolar cell transduction current. Application of 10 $\mu \mathrm{M}$ capsaicin, the prototypical TRPV1 agonist (Caterina et al., 1997), elicited a response in every rod bipolar cell that we examined (Fig. $2 A$ ) (mean amplitude, $14.8 \pm 1.4 \mathrm{pA} ; n=41)$. To examine the specificity of capsaicin, we applied it to Off bipolar cells, which were identified morphologically by dye filling and physiologically by their lack of response to LY341495. Application of capsaicin to Off bipolar cells produced no detectable response ( $n=4$; data not shown). We also recorded from rod bipolar cells in mice that were $8-9 \mathrm{~d}$ old. At this age, there was no detectable response to LY341495 or capsaicin ( $n=4$; data not shown), suggesting that the transduction cascade was not yet functionally developed. Finally, the response to capsaicin was completely blocked by capsazepine $(n=$ 2) (Fig. 2A).

The endocannabinoid anandamide, another agonist of TRPV1 receptors (Caterina et al., 1997; Jordt and Julius, 2002; van der Stelt et al., 2005), also elicited a response in rod bipolar cells (Fig. $2 B$ ) (mean amplitude, $9.6 \pm 1.7$ pA; $n=8$ ). The response to anandamide was inhibited by capsazepine $(34.8 \%$ of control; $n=2$ ) but was unaffected by the cannabinoid-1 receptor cell.
B
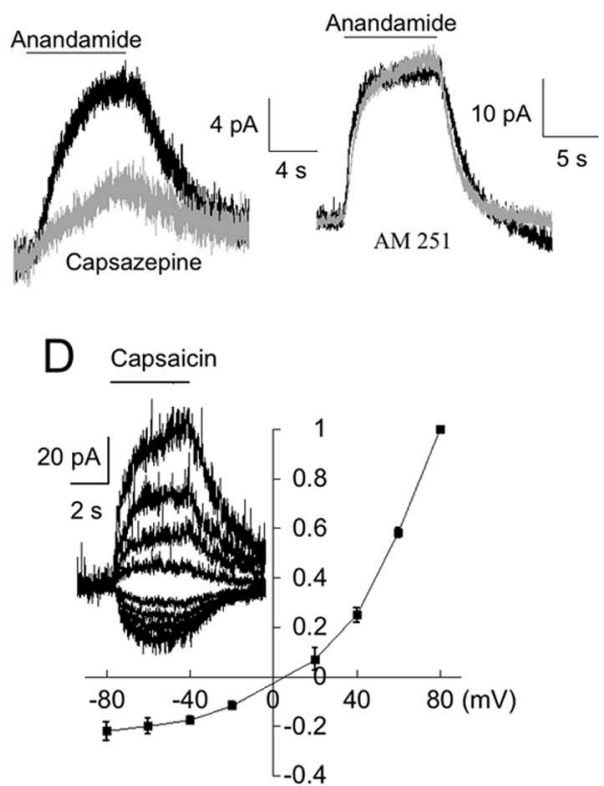

F Capsaicin-activated channel

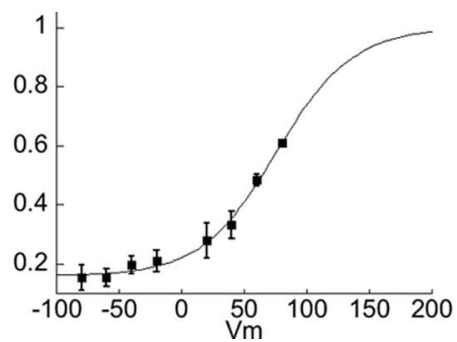

Figure 2. Rod bipolar cells respond to agonists of TRPV1. $A$, Response to a puff of $10 \mu \mathrm{m}$ capsaicin in normal solution (left) and traces, left and right) and solution containing $20 \mu \mathrm{m}$ capsazepine (gray trace, left) or $5 \mu \mathrm{m} \mathrm{AM251,} \mathrm{a} \mathrm{CB1} \mathrm{receptor} \mathrm{antagonist} \mathrm{(gray}$ trace, right). Left and right panels are from different cells. C, D, Summary I-V relations for LY341495 ( $n=7$ cells) and capsaicin ( 5 (ells). Peak currents were normalized to the response at $+80 \mathrm{mV}$ for each cell, and the results were pooled. Inset, increments. $\boldsymbol{E}, \boldsymbol{F}$, Plots of normalized conductance for the cells of the transduction channel and the capsaicin-gated channel. Lines are the fits to a Boltzmann function (see Materials and Methods). Plots were obtained from the same sets of cells whose $I-V$ relations are summarized in $C$ and $\boldsymbol{D}$, using the equation $g=I /\left(V_{\mathrm{m}}-V_{\text {rev }}\right)$, where $V_{\text {rev }}=0 \mathrm{mV}$, to obtain the conductance for each

antagonist AM251 (105.4\% of control; $n=3)$, indicating that it is not attributable to activation of cannabinoid receptors.

To more closely compare the transduction current and the current elicited by capsaicin, we measured the relationship between current and voltage by varying the holding potential from -80 to $+80 \mathrm{mV}$ in $20 \mathrm{mV}$ increments while applying either capsaicin or LY341495. An example of each is shown in the insets of Fig. 2, $C$ and $D$. At negative, but not positive voltages, the transduction current often displayed a prominent peak followed by a decay to a plateau, which has been previously shown to be $\mathrm{Ca}^{2+}$ dependent (Berntson et al., 2004; Nawy, 2004). To minimize the influence of $\mathrm{Ca}^{2+}$ on the $I-V$ relation, we measured the peak current, rather than the steady-state. For each cell, currents were normalized to the amplitude of the current at $+80 \mathrm{mV}$, and the results were pooled (Fig. 2C,D). The $I-V$ relations for both the native transduction current and the current evoked by capsaicin exhibited strong outward rectification. Furthermore, the mean reversal potential $\left(E_{\mathrm{rev}}\right)$ for each group were not significantly dif- 
ferent (LY341495: $E_{\mathrm{rev}}=-6.4 \pm 3.7 \mathrm{mV}, n=7$; capsaicin: $E_{\mathrm{rev}}=$ $-0.6 \pm 1.0 \mathrm{mV}, n=5 ; p>0.15$, unpaired Student's $t$ test).

By fitting the conductance of the transduction channel (Fig. $2 E$ ) with a Boltzmann function, we obtained a charge valance, $z$, of 0.80 and a $V_{1 / 2}$ of $+76.4 \mathrm{mV}$. The charge valence is much less than for voltage-gated channels such as the Shaker $\mathrm{K}^{+}$channel (Zagotta et al., 1994; Islas and Sigworth, 1999) but very similar to values obtained in TRP channels (Nilius et al., 2005). Fitting the capsaicin-activated conductance yielded similar values, with a $z$ of 0.87 and a $V_{1 / 2}=+75.9 \mathrm{mV}$ (Fig. $2 F$ ). Thus, both the voltage dependence and the pharmacology of the transduction channel in mouse rod bipolar cells are consistent with the properties of a TRP channel.

\section{Mutual occlusion of capsaicin and mGluR6-generated currents}

If the same population of channels is targeted by application of LY341495 and capsaicin, then one compound might be expected to occlude the actions of the other. To test this possibility, we applied LY341495 and capsaicin separately and measured the amplitude of the response to each. Next, we applied the two compounds simultaneously and again measured the response. When the duration of positive pressure application was sufficient to produce a maximal response to each drug, the response to the combination of both drugs was significantly less than predicted, based on linear summation of the responses obtained separately (Fig. $3 A, C$ ). The same result was obtained regardless of whether we measured the peak response $(p<0.01 ; n=7)$ or total charge transfer $(p<0.01 ; n=7)$ during drug application. This finding is consistent with the idea that both drugs compete for a limited number of channels. If this is the case, then lowering the concentration of each compound should reduce competition for the channel. To test this possibility, we reduced the amount of drug delivered to the rod bipolar cell by shortening the duration of the application (Fig. 3B). Under these conditions, the response to simultaneous delivery of both LY341495 and capsaicin coincided closely with a simple summation model (Fig. 3C). These findings support the idea that mGluR6 and capsaicin operate on the same population of channels.

\section{TRPM1, but not TRPV1, may play a role in mGluR6 transduction}

Two candidate channels for playing a role in the mGluR6 transduction pathway are TRPV1 and TRPM1. TRPV1 displays a similar pharmacology to the transduction channel as described above. However, TRPM1 has recently been implicated in transduction in the Appaloosa horse (Sandmeyer et al., 2007; Bellone et al., 2008). To address the possibility that one or both channels are a component of the transduction cascade, we recorded from two types of transgenic mice, one with a targeted deletion of TRPV1 (Caterina et al., 2000) and the other with a deletion of TRPM1 (Trpm $\left.1^{\text {tmlLex }}\right)$. The mGluR6 pathway appeared to be unperturbed in the TRPV1 ${ }^{-1-}$ mouse, as responses to LY341495, capsaicin, and anandamide were all present (Fig. $4 A$ ). Further analysis of both the $I-V$ relation and average amplitudes of the TRPV1 agonist responses failed to reveal any differences compared with wild-type animals (Fig. $4 B, C$ ). Similarly, the amplitude and kinetics of the b-wave of the ERG were virtually identical in wild-type and $\operatorname{Trp} v 1^{-1-}$ mice (Fig. 4D). Summary amplitudes of the b-wave, which is generated by On bipolar cell activity, and the a-wave which is generated by the activity of photoreceptors, are plotted as a function of light intensity in the right-hand panel of Figure $4 \mathrm{D}$. In contrast, measurements of
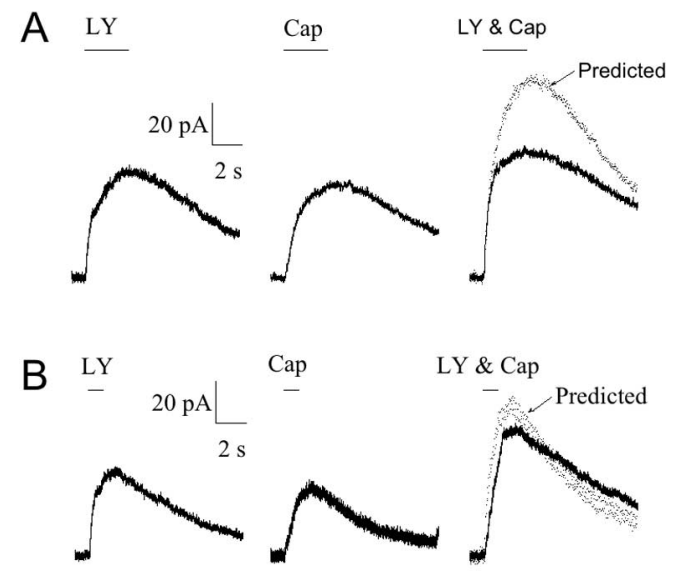

C

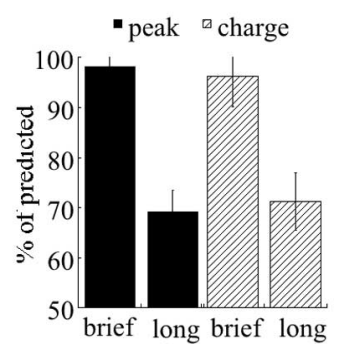

Figure 3. Responses to LY31495 and capsaicin occlude each other. $\boldsymbol{A}$, Responses to $3 \mathrm{~s}$ applications of LY341495 and capsaicin, first separately and then together. Also shown in the right panel is the predicted response to simultaneous application based on linear summation. $\boldsymbol{B}$, Similar to $\boldsymbol{A}$, except that the duration of the application was $1 \mathrm{~s}$. Note that for subsaturating application of drugs, the predicted response more closely approximates the response to simultaneous application of LY341495 and capsaicin. Same cell as in A. LY, LY31495; Cap, capsaicin. C, Comparison of evoked and predicted responses to simultaneous application of LY31495 and capsaicin as a function of puff duration. Long applications were for a duration of $3 \mathrm{~s}$, whereas brief applications were either $1 \mathrm{~s}$ or $0.5 \mathrm{~s}$. Charge was obtained by integration of current during the period of drug application. For both the peak response and the total charge transfer, there was no significant difference between the sizes of the predicted and actual responses to short puffs ( $p>0.5$; $n=7)$, but the response to long puffs was significantly smaller than predicted based on summation $(p<0.01 ; n=7)$.

ERG in the TRPM1 ${ }^{-1-}$ mouse revealed a complete lack of a b-wave but a normal a-wave, an indication that On bipolar cell function was completely disrupted (Fig. 4E).

\section{Discussion}

The identity of the postsynaptic channel that mediates synaptic transmission from photoreceptor to On bipolar cells is currently unknown. Here, we present evidence that the channel is likely to be a member of the family of TRP channels, perhaps TRPM1. The synaptic current is reduced by antagonists of TRP channels and mimicked by TRP channel agonists. Furthermore, the b-wave, which is thought to be generated by the opening of On bipolar cell synaptic channels, is normal in a TRPV1 knock-out mouse but completely eliminated in a mouse lacking functional TRPM1 channels. Our results are consistent with a recent study showing expression of TRPM1 RNA in mouse On bipolar cells (Kim et al., 2008). To date, a physiological characterization of TRPM1 has yet to be reported, and so it is unclear if this TRP channel can be gated by endovanilloids or whether TRPM1 currents rectify as do those of many other TRP channels. Although it is tempting to speculate that the current evoked by endovanilloids in rod bipolar cells is attributable to the opening of TRPM1 channels, confirmation of this hypothesis will require further investigation of the functional properties of TRPM1. 
A

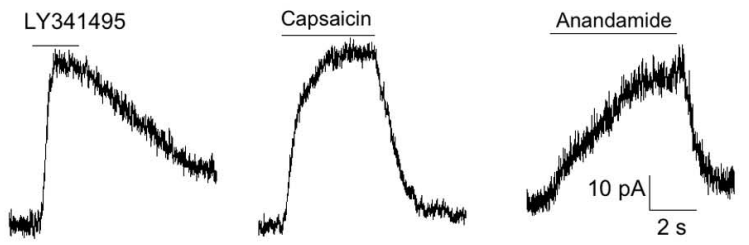

B

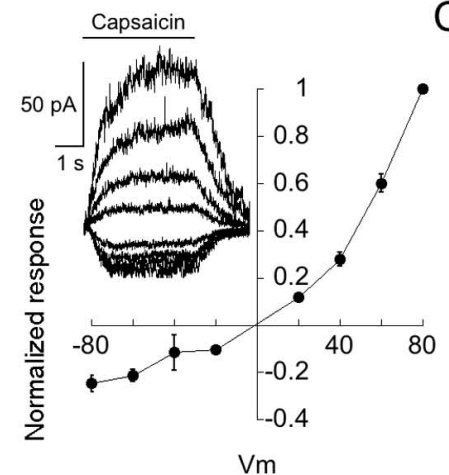

$\mathrm{C}$

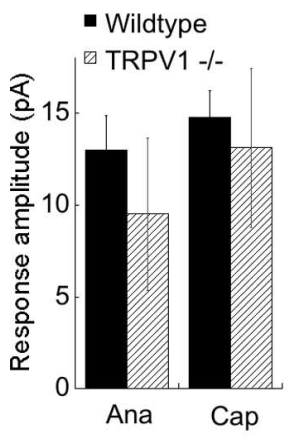

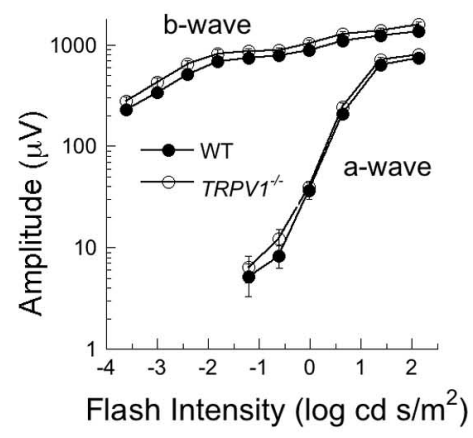

E WT

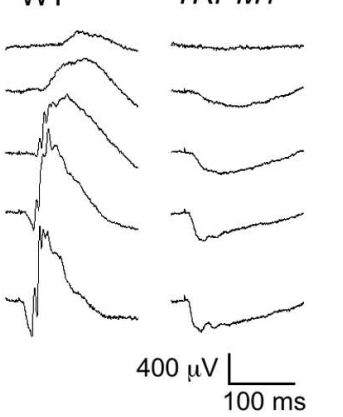

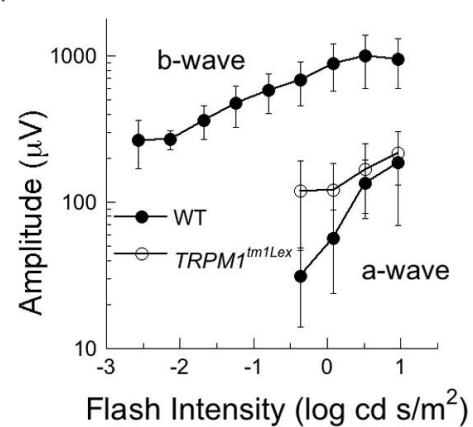

Flash Intensity $\left(\log \mathrm{cd} \mathrm{s} / \mathrm{m}^{2}\right)$

Figure 4. TRPV1 ${ }^{-1-}$ mice retain the transduction current, TRPV agonist activated currents and ERG b-waves; TRPM ${ }^{-1-}$ mice lack the ERG $b$-wave. $\boldsymbol{A}$, Examples of the responses to LY341495, capsazepine, and anandamide, indicating that both endogenous and exogenous gating of the transduction channel in the TRPV $1^{-1-}$ is preserved. $B$, Summary $/-V$ relation for capsaicin in TRPV1 $^{-1-}$ mice $(n=6)$. Inset, Responses to voltage steps from $-80 \mathrm{mV}$ to +80 $\mathrm{mV}$ in $20 \mathrm{mV}$ increments. $C$, Responses to both anandamide and capsaicin were not significantly different in amplitude between wild-type and TRPV1 ${ }^{-1-}$ mice. Ana, Anandamide (WT; $n=$ 13, TRPV $\left.^{-1-} ; n=4, p>0.25\right)$; Cap, capsaicin (WT; $n=41$, TRPV $^{-1-} ; n=15, p>0.50$ ). $D$, Left, Dark-adapted ERGs from a wild-type and a TRPV $1^{-1-}$ mouse. Flash intensities are (in $\left.\log c d s / m^{2}\right)-3.6,-2.4,-1.2,-0.0$, and 1.4. Right, Summary of the b-wave and a-wave amplitudes as a function of light intensity in wild-type $(n=8)$ and TRPV1 ${ }^{-1-}(n=6)$ mice. $\boldsymbol{E}$, Left, Dark-adapted ERGs from a wild-type and a TRPM1 ${ }^{-1-}$ mouse. Flash intensities are (in log $\left.\mathrm{cd} \mathrm{s} / \mathrm{m}^{2}\right)-2.6,-1.7,-0.8,0.1$, and 1.0. Right, Summary of the b-wave and a-wave amplitudes as a function of light intensity in wild-type $(n=3)$ and TRPM1 ${ }^{-1-}(n=4)$ mice. For $T_{R P M 1}{ }^{-1-}$, only the a-wave data are plotted, as there was no measurable positive-going response.

Our findings are consistent with the findings of several recent studies of bipolar cell function in Appaloosa horses. In these horses, there is a link between a specific pattern of coat coloration and congenital stationary night blindness (Sandmeyer et al., 2007). Animals with this coloration lack the ERG b-wave, indicating a loss of function of On bipolar cells, although the structure of the retina appears normal (Witzel et al., 1978). Genetic analysis of this phenotype revealed decreased expression of mRNA encoding TRP channel TRPM1 (Bellone et al., 2008). Of course, the loss of On bipolar cell function could potentially result from a number of underlying etiologies other than a mutation in the transduction channel (McCall and Gregg, 2008). Nevertheless, an intriguing possibility, based on the results presented here and previous work on the Appaloosa horse, is that the transduction channel in the dendrites of rod bipolar cells is composed of TRPM1, either as a homomer or in association with other TRP channels.

\section{References}

Bellone RR, Brooks SA, Sandmeyer L, Murphy BA, Forsyth G, Archer S, Bailey E, Grahn B (2008) Differential gene expression of TRPM1, the potential cause of congenital stationary night blindness and coat spotting patterns (LP) in the appaloosa horse (Equus caballus). Genetics 179:1861-1870.

Berntson A, Smith RG, Taylor WR (2004) Postsynaptic calcium feedback between rods and rod bipolar cells in the mouse retina. Vis Neurosci 21:913-924.

Caterina MJ, Schumacher MA, Tominaga M, Rosen TA, Levine JD, Julius D (1997) The capsaicin receptor: a heat-activated ion channel in the pain pathway. Nature 389:816-824.

Caterina MJ, Leffler A, Malmberg AB, Martin WJ, Trafton J, Petersen-Zeitz KR, Koltzenburg M, Basbaum AI, Julius D (2000) Impaired nociception and pain sensation in mice lacking the capsaicin receptor. Science 288:306-313.

Clapham DE (2007) SnapShot: mammalian TRP channels. Cell 129:220, e220-e222.

Craven KB, Zagotta WN (2006) CNG and HCN channels: two peas, one pod. Annu Rev Physiol 68:375-401.

Dhingra A, Lyubarsky A, Jiang M, Pugh EN Jr, Birnbaumer L, Sterling P, Vardi N (2000) The light response of ON bipolar neurons requires $\mathrm{G} \alpha$. J Neurosci 20:9053-9058.

Gregg RG, Kamermans M, Klooster J, Lukasiewicz PD, Peachey NS, Vessey KA, McCall MA (2007) Nyctalopin expression in retinal bipolar cells restores visual function in a mouse model of complete X-linked congenital stationary night blindness. J Neurophysiol 98:3023-3033.

Hartwick AT, Bramley JR, Yu J, Stevens KT, Allen CN, Baldridge WH, Sollars PJ, Pickard GE (2007) Light-evoked calcium responses of isolated melanopsin-expressing retinal ganglion cells. J Neurosci 27: $13468-13480$.

Islas LD, Sigworth FJ (1999) Voltage sensitivity and gating charge in Shaker and Shab family potassium channels. J Gen Physiol 114:723-742.

Jordt SE, Julius D (2002) Molecular basis for species-specific sensitivity to "hot" chili peppers. Cell 108:421-430.

Kim DS, Ross SE, Trimarchi JM, Aach J, Greenberg ME, Cepko CL (2008) Identification of molecular markers of bipolar cells in the murine retina. J Comp Neurol 507:1795-1810.

Koplas PA, Rosenberg RL, Oxford GS (1997) The role of calcium in the desensitization of capsaicin responses in rat dorsal root ganglion neurons. J Neurosci 17:3525-3537.

Liu L, Simon SA (1996) Capsaicin-induced currents with distinct desensitization and $\mathrm{Ca} 2+$ dependence in rat trigeminal ganglion cells. J Neurophysiol 75:1503-1514.

McCall MA, Gregg RG (2008) Comparisons of structural and functional abnormalities in mouse b-wave mutants. J Physiol 586:4385-4392.

Nakajima Y, Iwakabe H, Akazawa C, Nawa H, Shigemoto R, Mizuno N, Nakanishi S (1993) Molecular characterization of a novel retinal metabotropic glutamate receptor mGluR6 with a high agonist selectivity for L-2-amino-4-phosphonobutyrate. J Biol Chem 268:11868-11873.

Nawy S (1999) The metabotropic receptor mGluR6 may signal through $G_{o}$, but not phosphodiesterase, in retinal bipolar cells. J Neurosci 19:2938-2944. 
Nawy S (2000) Regulation of the On bipolar cell mGluR6 pathway by $\mathrm{Ca}^{2+}$. J Neurosci 20:4471-4479.

Nawy S (2004) Desensitization of the mGluR6 transduction current in tiger salamander On bipolar cells. J Physiol 558:137-146.

Nawy S, Jahr CE (1990) Suppression by glutamate of cGMP-activated conductance in retinal bipolar cells. Nature 346:269-271.

Nilius B, Talavera K, Owsianik G, Prenen J, Droogmans G, Voets T (2005) Gating of TRP channels: a voltage connection? J Physiol 567:35-44.

Nomura A, Shigemoto R, Nakamura Y, Okamoto N, Mizuno N, Nakanishi S (1994) Developmentally regulated postsynaptic localization of a metabotropic glutamate receptor in rat rod bipolar cells. Cell 77:361-369.

Piper AS, Yeats JC, Bevan S, Docherty RJ (1999) A study of the voltage dependence of capsaicin-activated membrane currents in rat sensory neurones before and after acute desensitization. J Physiol 518:721-733.

Ramsey IS, Delling M, Clapham DE (2006) An introduction to TRP channels. Annu Rev Physiol 68:619-647.

Sandmeyer LS, Breaux CB, Archer S, Grahn BH (2007) Clinical and electroretinographic characteristics of congenital stationary night blindness in the Appaloosa and the association with the leopard complex. Vet Ophthalmol 10:368-375.

Sekaran S, Lall GS, Ralphs KL, Wolstenholme AJ, Lucas RJ, Foster RG, Hankins MW (2007) 2-aminoethoxydiphenylborane is an acute inhibitor of directly photosensitive retinal ganglion cell activity in vitro and in vivo. J Neurosci 27:3981-3986.
Shiells RA, Falk G (1990) Glutamate receptors of rod bipolar cells are linked to a cyclic GMP cascade via a G-protein. Proc Biol Sci 242:91-94.

Shiells RA, Falk G (1999) A rise in intracellular Ca2+ underlies light adaptation in dogfish retinal 'on' bipolar cells. J Physiol 514:343-350.

Shiells RA, Falk G, Naghshineh S (1981) Action of glutamate and aspartate analogues on rod horizontal and bipolar cells. Nature 294:592-594.

Slaughter MM, Miller RF (1981) 2-Amino-4-phosphonobutyric acid: a new pharmacological tool for retina research. Science 211:182-185.

Snellman J, Nawy S (2004) cGMP-dependent kinase regulates response sensitivity of the mouse on bipolar cell. J Neurosci 24:6621-6628.

van der Stelt M, Trevisani M, Vellani V, De Petrocellis L, Schiano Moriello A, Campi B, McNaughton P, Geppetti P, Di Marzo V (2005) Anandamide acts as an intracellular messenger amplifying Ca2+ influx via TRPV1 channels. EMBO J 24:3026-3037.

Vardi N, Matesic DF, Manning DR, Liebman PA, Sterling P (1993) Identification of a G-protein in depolarizing rod bipolar cells. Vis Neurosci 10:473-478.

Warren EJ, Allen CN, Brown RL, Robinson DW (2006) The light-activated signaling pathway in SCN-projecting rat retinal ganglion cells. Eur J Neurosci 23:2477-2487.

Witzel DA, Smith EL, Wilson RD, Aguirre GD (1978) Congenital stationary night blindness: an animal model. Invest Ophthalmol Vis Sci 17:788-795.

Zagotta WN, Hoshi T, Dittman J, Aldrich RW (1994) Shaker potassium channel gating. II: Transitions in the activation pathway. J Gen Physiol 103:279-319. 